\title{
An Advanced Demonstration of Library Based Approach to the Initial Design Exploration of Different Hullform Configurations
}

\author{
Tim P McDonald ${ }^{\text {ab }}$, David J Andrews ${ }^{\text {ac }}$ and Richard G Pawling ${ }^{\text {ad }}$
}

\begin{abstract}
The importance of requirement elucidation, in shaping both the customers' needs and initial solutions during the concept stage of the ship design process, has previously been emphasised in the choice of initial design methods. It is well known that alternative hullform styles can bring distinct performance benefits in certain design investigations. However, current design methods or tools suitable for exploring alternate hullform styles during requirement elucidation do not readily facilitate this. This paper describes a library based ship concept design tool and its ability include exploration of hullform options in the initial exploratory stage of the ship design process. The library based approach utilises substructuring to describe the design in terms of four functional subsets to increase the efficiency of the search process. The example presented looks at monohull, catamaran and trimaran hullform options for a fast naval combatant. The paper concludes with the advantage seen in the tool in concert with a configuration oriented approach to ship design, namely, the Design UCL Building Block approach.
\end{abstract}

\section{Key Words}

Initial Ship Design; Requirement Elucidation; Library Method; Hullform Selection; Multihullforms.

\section{Introduction}

A paper by the first two authors was given to the 2009 International Marine Design Conference, in Trondheim [1]. This presented a Library based ship concept design approach by justifying the need for such an approach, explaining the logic behind the approach and giving an example of the use of the approach to explore the options for a frigate sized naval vessel in the 3,500 to 6,000 tonne displacement range. That paper indicated that a virtue of the approach was to be able to explore not just variations in a conventional monohull combatant but, at the same time, to extend this to consideration of other hull configurations. Thus it was intended that the Library based approach should be used to explore unconventional ship configurations, such as multihulls and advanced hull forms. The approach has subsequently been extended to undertake the initial design exploration of monohull options, alongside catamaran and trimaran options and this is reported in the current paper.

The paper commences with a summary review of the justification for such a Library approach to initial design exploration by considering current preliminary ship design methods, their perceived limitations and what has been proposed as the necessary features for initial ship design methods, if they are to be comprehensive and foster a creative exploration of design options. The Library based approach is then summarised showing how it relies on a division of the ship sizing key variables into functional categories. The categories chosen are those of: Float; Move; Fight (in the case of a naval combatant) or Operations (in the case of a commercial ship with a cargo or service function); and, Infrastructure. Originally these functional categories were adopted by the second author for an architecturally based synthesis [2], which was developed into the UCL Design Building Block approach [3,4]. The paper then outlines the application of the Library based approach to the initial ship synthesis of the previously demonstrated monohull frigate explored in Reference 1, but now importantly including consideration of alternative vessel styles (in this case for catamaran and trimaran hullforms). This allows an exploration of a wide range of solutions, avoiding the limitation of many existing synthesis techniques, which experience difficulty in concurrently assessing multiple styles. The final section of the paper considers the wider implications of the comprehensive hullform synthesis and comparison, together with the implications for initial ship design. This includes consideration as to how the Library based approach can be combined with the Design Building Block approach to open up the exploration of both the widest range of ship configurations and to be responsive to the simulation based consideration of a range of aspects of design style [5]. The style issues importantly include those driven by human factors considerations, which have been previously excluded from initial ship design synthesis [6].

\footnotetext{
a Marine Research Group, Department of Mechanical Engineering, UCL, London, UK

${ }^{\mathrm{b}}$ Corresponding author: Tel. +442076797063; Fax.+442076797065; E-mail t.mcdonald@ucl.ac.uk

${ }^{\mathrm{c}}$ E-mail.d_andrews@meng.ucl.ac.uk

dE-mail.r_pawling@meng.ucl.ac.uk
} 


\section{The Need To Explore Hullform Comparison In Initial Ship Design}

The issue in the initial design of complex ships, such as naval combatants, is that the exploration should be as wide as possible so that all conceivable options are explored and the emergent requirements are "elucidated" from this comprehensive exploration. Importantly this exploration informs the dialogue between the requirement owner and the concept ship designer [7]. Until now the exploration of alternative hullforms or even radical configurations, within the (classical) monohull ship shape, have had to be synthesised and analysed for performance sequentially, if at all. This was encapsulated by Reference 1 in stating:

"to explore the widest possible solution space including modifying existing ships, packaging the capability and exploring high and low technology options to determine the region of interest in the solution space... should be both an exploratory and divergent process, allowing the designer to consider radical alternatives."

The IMDC 2009 State of the Art Report on Design Methodology, edited by the second author [8], showed some twenty six approaches to modelling the ship design process, most of which focused on the initial design phases. These and the six general categories of ship design methods (Traditional, Configuration based, Decision Making, Concept Exploration Artificial Intelligence and Optimisation), identified in Table 2 of Reference 1, fail to address how the consideration of hull form comparison can be seamlessly encompassed in the initially synthesis. Currently this consideration can be undertaken, at best, through a separate investigation or exploration by separately synthesis process modelling each alternative hulfform configuration. This is recognised as a problem, in that either such a comprehensive exploration is rejected, as being inefficient, or even worse, is not addressed in initial design. This then means the initial concept exploration is restricted, with potential solutions unconsidered, and the elucidation of the requirements is constrained, leading to downstream vulnerabilities in requirement justification and the project approval process.

In examining the six types of ship design method considered in Reference 1, it was concluded that all six restrict the designer's ability in hullform selection in the early stages of the ship design process. However, the extent of this restriction varies between the methods. Some, such as the traditional numerical ship synthesis and the DBB approach, are restricted by the inherent limits of human cognitive speed to consider more than one ship design type at a time. Whereas those relying on (numeric) selection processes, such as expert systems, neural networks and genetic algorithms, are restricted by the simplistic nature, in regard to appreciation of variations in ship configuration, of current machine based applications using such decision-making tools. From these two different limitations the common topic of decision making emerges as a key initial design task.

Two extremes exist with regard to decision-making methods: involved decision methods or detached decision methods. Involved decisions methods (such as the Design Building Block approach [3]) ensure the designer makes the design decisions. Detached decision methods (such as optimisation based approaches, see Table 1 of [9]) employ a design tool that uses objectives and constraints to find a best solution. These two types of methods have also been termed glass and black boxes respectively [10]. In general, involved methods enable the designer to gain a detailed understanding of the factors that are revealed to be crucial or driving a small number of solutions. In comparison, detached methods are amenable to automation and hence have the potential to be used to rapidly assess a large number of options to select a proposed solution. However, at the first stage of the design process the designer may actually wish to explore a large number of solutions to develop their understanding, as opposed to finding a single 'best' solution or obtaining a high degree of understanding of a single specific 'detailed' solution. Given current design methods largely focus on obtaining a 'best' solution rather than providing knowledge of the potential solution space, what is wanted is a way of exploring a large number of potential designs that leaves the designer in control, by the open exploration revealing valuable insights, i.e. combining the virtues of both sets of methods.

Given the importance of the designer fully exploring potential options, as part of the concept phase of the ship design process, there remains a difficulty in that the number of options the designer can explore is always going to be limited by design imperatives (i.e. manpower, time and funds). The process of requirement elucidation, as the driving motivation in early ship design, adds a further complication. If, as a necessary part of a comprehensive early design process, the designer is also to consider different hullform styles - with widely varying characteristics and performance-then the need to find a more speedy manner to undertake a wide exploration of options becomes more challenging.

Current ship design methods fail to provide a tool that adequately addresses this issue. This is due to the fundamentally solution centric approach that they adopt, typified by the following broad scheme: take initial/proposed inputs, develop a whole ship solution, evaluate performance, and then iterate by adjusting the inputs. This approach can be seen to not be suited to the exploratory phase of the design process where designers wish to develop their understanding of the potential solution space. Additionally, emerging requirements (typically revealed through requirement elucidation (7) in this stage) normally radically alter the solution space, rendering existing the 'best' solutions outmoded. Retaining a substantial number of feasible but non-optimal designs can allows the incorporation of additional knowledge, developed "a posteriori" during the design, while limiting the influence of erroneous priorities on the direction of the design study [11]. 
At this point it is useful to consider the features ship designers have previously requested in a concept design tool. Betts [12] provides a useful checklist for the required capabilities of a warship design tool:

1. "Utilise data for assessment of performance, risk and through life cost;

2. Usable by a knowledgeable design team;

3. Deal comparably with conventional and unconventional ship concepts;

4. Provide reasonable (preliminary) solutions;

5. Assist communications with design team and all stakeholders, especially those evolving the operational requirement."

Additionally, Andrews [13] considers there to be five features required to be exhibited in the outcome of any approach to preliminary ship design, if this is to meet the demands of requirement elucidation:

1. "Believable solutions, meaning ones that are both technically balanced and descriptive;

2. Coherent solutions, meaning that the dialogue with the customer should be more than merely a focus on numerical measures of performance and cost, and should include visual representation;

3. Open methods, in that they are responsive to the issues that matter to the customer or are capable of being elucidated from the customer or from user teams;

4. Revelatory, so likely design drivers are identified early in the design process to aid effective design exploration;

5. Creative, in that options are not closed down by the design method and tool but rather alternatives are fostered."

These two sets of features can be used as benchmarks in judging whether a proposed design approach is attractive in meeting the designer's needs, early in the design process when the topic of hullform selection should be tackled. These features are seen to be different from those required for a tool intended to be used later in the design process where the main motivation is to derisk and develop detailed design definitions appropriate to build and operate a new design.

Ideally, a design method or tool able to support hullform selection, in the exploratory phase of the ship design process, should assist the designer in understanding the customer's needs and hence assist the designer in the dialogue with the customer to elucidate the ship's requirements. It should capture the impact of these changing requirements on possible solutions. It should allow the consideration of different hullform styles and not unduly constrain the designer to a limited selection of hullform types. It must be sufficiently flexible to allow the addition of new information by the designer as it becomes available. It should aim to fulfil Betts' list of preliminary design tool needs and Andrews' list of creative ship design system features. Finally, the method should strive to support different types of ship design, in terms of the increasingly demanding technological novel solutions, ranging from simple batch development right through to designs with radical technologies and configurations [14].

\section{The Library Based Ship Concept Design Approach}

Reference 1 presented the UCL Library Based approach to initial ship design. In essence this approach is based upon a limited library of possible options able to describe a large number of ship designs, which the designer can rapidly filter to find options that satisfy the current design requirements.

The initial library must be broad enough to contain an array of options that will be of interest to the designer. However, it is apparent that the number of options within the library can rapidly expand and soon become unmanageable. Thus a process of decomposition and down selection is required to reduce the number of options that have to be stored within the library. If a ship option is decomposed into a number of sub-options then these can be stored in place of whole ship options. The sub-options have then to be combined to produce a far larger set of possible whole ship options, which have been termed 'combined options' [1].

The options from the library could be filtered via a number of different search mechanisms, such as those employed within database tools [15]. The power and speed of current search techniques should be familiar to any user of Internet search engines. By assessing the options' pre-calculated characteristics and performance, a rapid down selection process can be easily implemented. Furthermore, if part of this down selection process occurs at a sub-option level, by making use of an appropriate subset of the requirements, this can significantly reduce the number of combined options that need to be considered. The possible combinations of remaining sub-options can then be used to produce a set of combined options. Finally, the set of combined options, which meet the overall constraints and requirements, can be obtained.

A number of different approaches to decomposition exist, such as using a weight group or system level breakdown. However, given the motivation to provide the designer with a means of evaluating different hullforms, the functional group breakdown adopted by Andrews and Dicks [3] is seen to be advantageous. Using this the ship is decomposed into four functional groups: Float, Move, Operation (or Fight) and Infrastructure. This can be seen from the frigate example considered in Reference 1 and its characteristic relationships are shown below at Figure 1. The values of these characteristics have been obtained using the UCL MSc design procedure, which give a set of equations linking the 
dimensions, weight and volume for a monohull warship can be selected [16,17]. By examining these equations a set of relationships is revealed, which matches the functional categories adopted for the UCL DBB approach.

Figure 1 collects together the key variables in the sizing equations from the UCL ship design procedure. For each key variable listed along the top of the figure the variables upon which it directly depends are indicated in the column below (using a - symbol). For example, the UCL sizing procedure defines draught through a relationship between displacement, volume and depth. The columns in Figure 1 have been arranged to collect variables in clusters of closely related properties. These clusters can be seen to match those used when decomposing a ship into the Float, Move, Fight and Infrastructure functional groups. Other authors have proposed applying decomposition in ship design but not related the decomposition specifically to these (DBB) functional groups [18]. Additionally, a fourth cluster emerges for those variables describing whole ship characteristics, which are similar to general ship characteristics defined in [5]. Current numerically based design methods iterate the whole ship properties in the lower left hand cluster of Figure 1 until a balanced solution emerges.

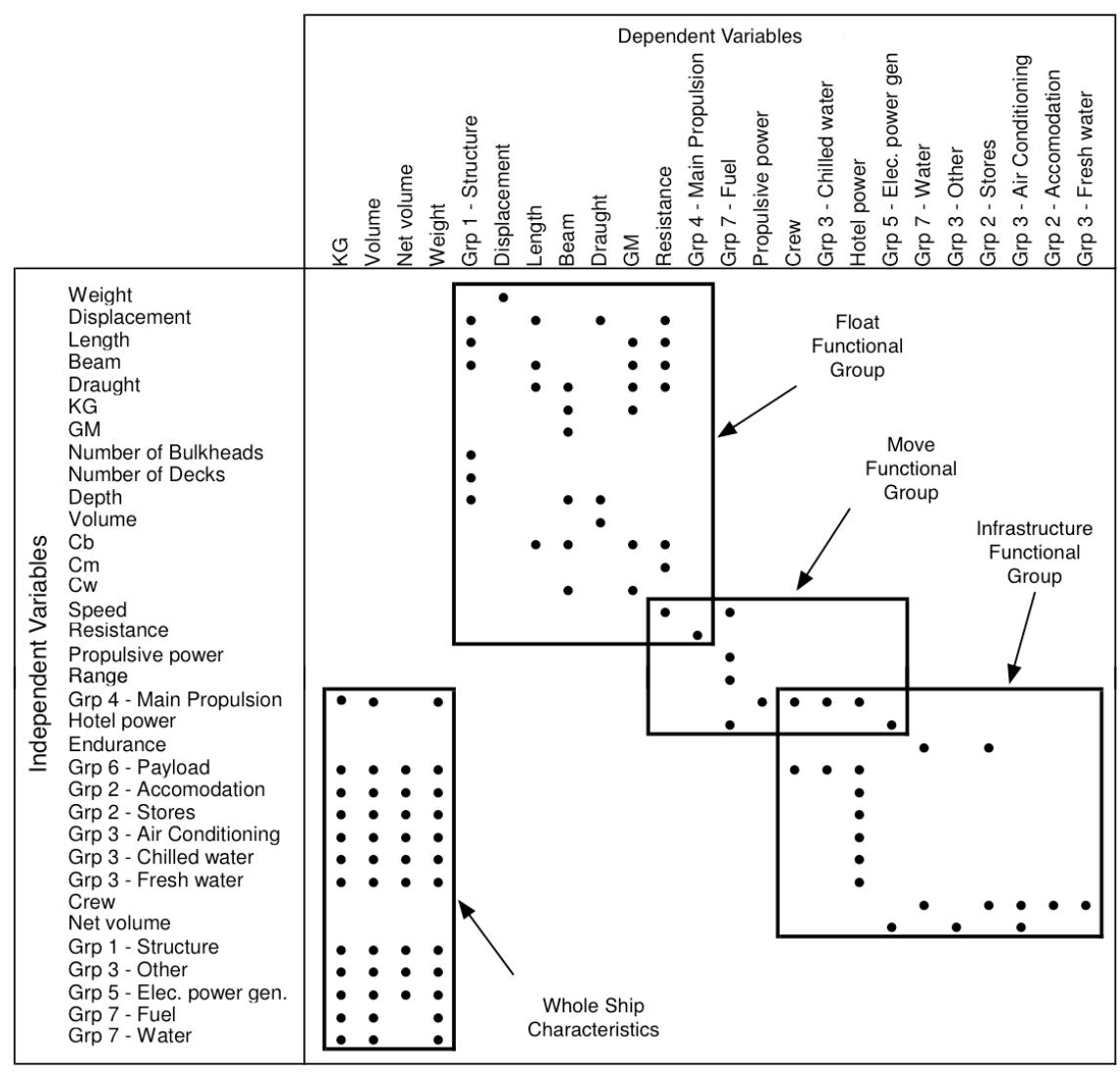

Figure 1: Clustered Relationships for a Frigate Design showing the Key Variable, based upon data from UCL $[16,17]$

A number of the properties that are difficult to predict, such as resistance and propulsion, can be seen to lie within a specific functional cluster. If complex prediction methods are considered some of these can be similarly constrained to a single cluster (i.e. seakeeping and large angle stability are predominantly dependent upon the hullform shape, displacement and the position of the vertical centre of gravity and, hence, the Float function). For these properties, which are difficult to predict, it is sensible to pre-calculate their values using appropriate tools then store these values within the library. In comparison, some overall vessel properties are comparatively easy to evaluate (i.e. weight and volume are simple summations of scalar values) and can be rapidly determined from the properties of the sub-options that make up the combined option.

It is appreciated that there are a number of other properties that will be far more difficult to predict. The majority of these appear to be strongly driven by layout. For example, survivability is a strong driving factor in warship concept design. Current methods used to assess survivability require a highly detailed design to be produced [19]. Consequently, the large number of interrelated variables then under consideration will complicate the application of this decomposition method, incorporating such considerations. However, some elements of the survivability calculation (e.g. damaged stability or blast propagation) could be performed at a functional group level. This would still provide information that will be informative for a designer in arriving at early configurational choices. 
Figure 2, summarises the process of using a library of sub-options, based on the Float-Move-Fight-Infrastructure functional breakdown and using a set of intended operational requirements to build up the ship. The latter are used to consider the "Fight" element in the last step in the Library "synthesis". At the left of Figure 2(a) are the sub-options for the three functional groups $\left(\mathbf{S}_{\mathbf{F}}, \mathbf{S}_{\mathbf{M}}, \mathbf{S}_{\mathrm{I}}\right)$ that are stored within the library. These sub-options are then assessed against appropriate subsets of the ship requirements $\left(R_{F}\right.$ for the Float options, $R_{M}$ for the Move options and $R_{I}$ for the Infrastructure options), with those that fail to meet given thresholds of specific performance criteria being removed from consideration. The subsets of the requirements will differ between the functional groups, for example a Float sub-option could be removed from consideration by using an overall length requirement to remove the inappropriate hullforms (e.g. those too long to meet docking constraints or those too short to accommodate the combat system equipment on the upper

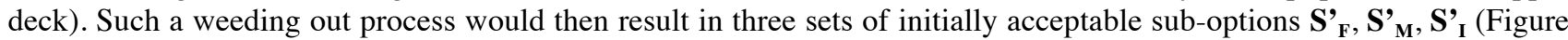
2(b)). By employing the mapping spelt out in Reference 1, three sets of sub-options can be combined into a new set of combined ship options, which at this stage exclude the operational items' demands $\mathbf{S}_{(\mathrm{S}-\mathbf{0})}$ (Figure 2(c)). Once again the remaining ship related requirements can be used to delete the unacceptable options from the set of combined ship options that exclude the operational items' demands $\mathbf{S}_{(\mathrm{S}-\mathbf{O})}$. Hence, $\mathbf{S}_{(\mathrm{S}-\mathbf{O})}$ is down selected using both those requirements originating from the demands of the Operations functional group $R_{O}$ (e.g. those without enough available space to accommodate the operational, infrastructure and machinery items) and those ship requirements $R_{S}$ that encompass other customer needs and span several functional groups (e.g. an endurance requirement for a particular speed). When assessing some of these requirements, performance prediction methods may need to be employed to predict values not stored within the Library. Additionally, performance prediction methods could be used to better account for major interactions between sub-options, e.g. when comparing a combined option's required propulsive power for a certain speed (derived from the Float sub-option) against the options installed power (derived from the Move sub-option). In these cases an appropriate correction may need to be applied (using a fast calculation method [20]) in order to successfully complete the down selection. This will result in the final set of acceptable combined ship options that can accommodate the payload $\mathbf{S}_{\mathbf{S}}$ (Figure 2(d)). This collection of options would then be presented by the tool's output to the designer.

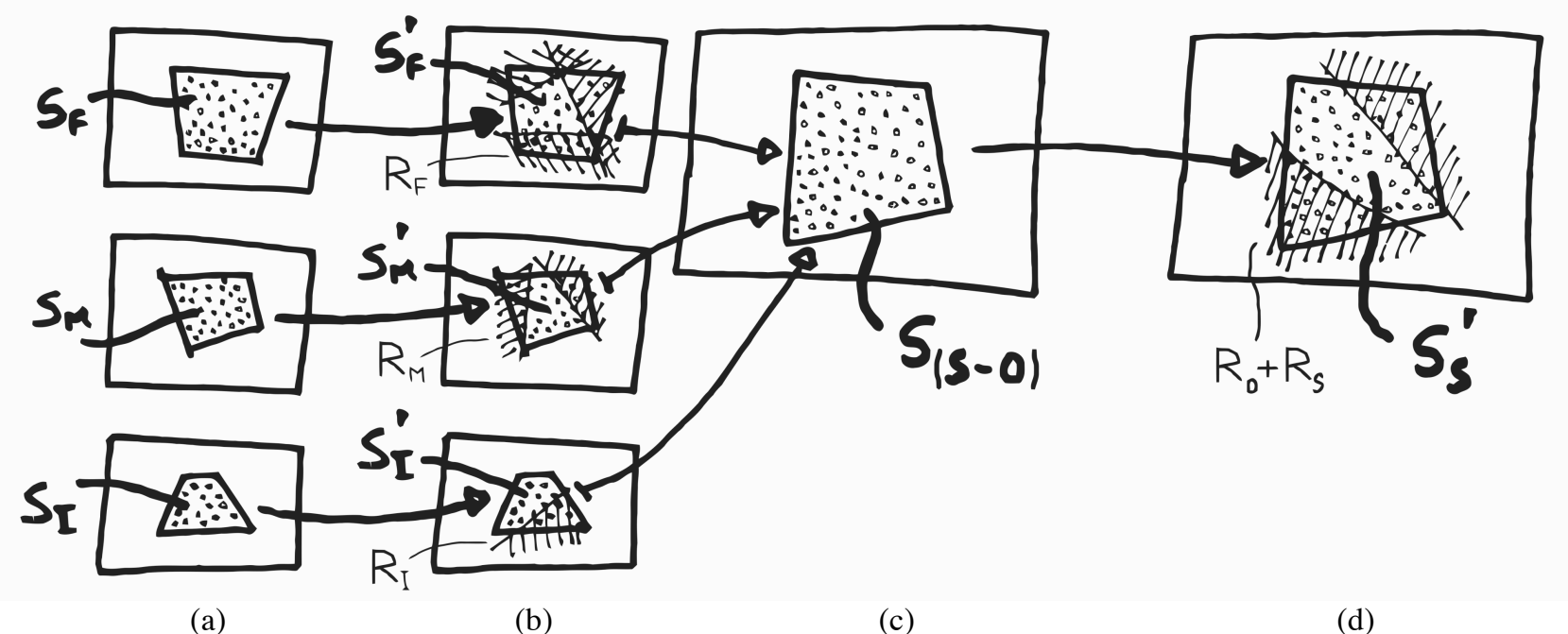

Figure 2: Iconic Representation of Option Exploration Process Based on a Set of Functional Ship Sub-Options

\section{Presentation Of Library Based Synthesis With Different Hullform Ship Solutions}

This section outlines a library based ship concept design approach that uses a database backed object-oriented programming approach to rapidly explore a number of alternative hullforms. This is done using a library containing a number of different hullforms and sets of requirements, selected from a recent and actual naval ship design programme.

Adopting a database storage system enables the down selection process to make use of the database's rapid search and query capabilities. Items returned by the database can then be realised as instances of objects within the implementation. These instances can then be sorted and combined with pointers, referring to the original objects containing the data. Thus they do not need to be duplicated, avoiding a computational task that is both demanding in processing and intensive in memory capacity. Adopting an object based implementation also enables radically different solutions to be more easily represented, stored and retrieved. This then allows the library to hold options representing a range of design styles, including hullform configurations. However this requires an appropriate format for items stored with the library. This specific implementation is built using a number of different objects that act together to create a data model able to 
perform the key tasks underlying the approach outlined in the previous section. Seven primary types of objects, which are explained in the following paragraph, make up the improved implementation:

- Items;

- Characteristics;

- Values;

- Conditions;

- Functions;

- Styles;

- Characteristic Types.

Each option (or sub-option) in the Library is defined using a single Item object linked to a number of Characteristic objects that describe the Item's features. Characteristics are organised using common Characteristic Types object (such as 'Length', 'Weight' and 'Power supplied'). As an option may operate in a number of different modes or states, each Item can also be allocated a number of Condition objects that define these differing operating conditions. The actual value a Characteristic possesses can by recorded in two ways, either a single numerical value stored as an attribute within each Characteristic or a number of relationship to several Value objects, each of which define the characteristics value in a particular condition (i.e. the required propulsive power corresponding to a particular operating speed).

The seven object types are illustrated in Figure 3. The diagram shows each object's attributes (the variables stored within the object) and the relationships the object has to other objects in the Library. A line terminating with two single arrows denotes a one-to-one relationship. A line terminating in one single arrow and one double arrow denotes a one-to-many relationship. Finally, a line terminating in two double arrows denotes a many-to-many relationship. For example, an Item object may contain relationships linking it to a number of Characteristic objects while each Characteristic object can only be related to a single Item object, this relationship can be defined as a one-to-many relationship. This description of the objects with their relationships allows the objects within the Library to be mapped to a relational database structure, which allows storage and rapid retrieval, given a set of constraints.

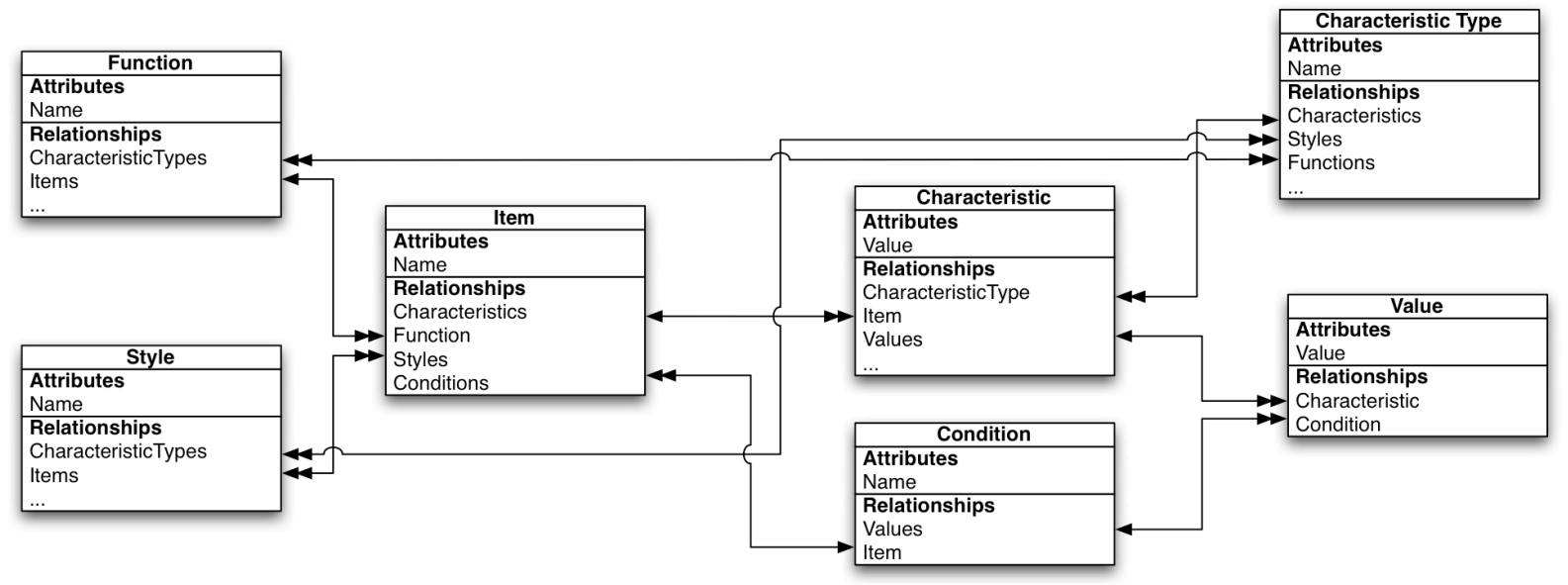

Figure 3 - Key Objects within the Library

Each Item within the improved implementation must be assigned a relationship to a Function object (i.e. 'Float', 'Move', etc.) and a number of Style objects (i.e. different hullform types: 'monohull', 'SWATH', 'trimaran', etc.). Function objects represent the different functional elements of an option, all Items objects in the library belong to a specific part of the functional decomposition applied to the overall system (i.e. whole ship) represented in the library. Table 1 shows an example of a functional hierarchy from within the design and used in Float, Move, Fight and Infrastructure breakdown proposed by Andrews and Dicks [3]. 
Table 1 - Portion of a Ship Function Hierarchy showing typical example Characteristics

\begin{tabular}{ll}
\hline Functions & Example Characteristics Required for Function \\
\hline Ship & Weight Available; Volume Available; Cost. \\
$\rightarrow$ Float & Overall length; Overall beam; Maximum draught; Resistance-Speed ${ }^{\mathrm{a}}$. \\
$\rightarrow$ Sustension & Displacement. \\
$\rightarrow$ Subdivision & Bulkhead positions. \\
$\rightarrow$ Strength & Maximum bending moment. \\
$\rightarrow$ Move & Thrust-Operating duration ${ }^{\mathrm{a}}$. \\
$\rightarrow$ Propulsion & Thrust-Fuel consumption ${ }^{\mathrm{a}}$. \\
$\rightarrow$ Transmission & Fuel consumption-Power output-RPM ${ }^{\mathrm{a}}$. \\
$\rightarrow$ Propulsors & Power input-Power output-RPM ${ }^{\mathrm{a}}$. \\
$\vdots$ Energy storage & Power input-RPM-Thrust ${ }^{\mathrm{a}}$. \\
\hline
\end{tabular}

${ }^{a}$ These characteristics normally consist of a set of values for different conditions.

An additional mechanism, that of Style, needs to be employed to for distinguishing between options with identical (functional) roles but which are radically differently configured. With regard to the hullform, a number of different styles are conceivable due to different source of lift or the topology of the major components of the hullform. As an option may posses multiple styles (i.e. trimaran, double hulled, steel) the library structure allows each Item object to be assigned a relationships to several Style objects. Table 2 shows an example of a hierarchy of styles. Styles also inherit the characteristics of their parent items in the hierarchy (e.g. the Catamaran Style expresses the following characteristics: Overall length; Overall beam; Displacement; Resistance-Speed; Demi-hull separation; Box clearance; Demi-hull waterline beam; and Demi-hull waterline length).

Table 2 - Portion of a Style Hierarchy for a range of Hullform Styles showing typical example Characteristics

\begin{tabular}{ll}
\hline Functions & Example Characteristics Required for Style \\
\hline Base Hullform Style & Overall length; Overall beam. \\
$\rightarrow$ Hydrostatic Sustension & Displacement; Resistance-Speed \\
$\rightarrow$ Monohull & Waterline beam; Waterline length. \\
$\rightarrow$ Twin-hull & Demi-hull separation; Box clearance. \\
$\rightarrow$ Catamaran & Demi-hull waterline beam; Demi-hull waterline length. \\
$\rightarrow$ SWATH & Bulb radius; Strut length; Strut beam. \\
$\rightarrow$ Tri-hull & Side-hull separation. \\
$\rightarrow$ Trimaran & Main hull waterline beam; Main hull waterline length; Side hull waterline beam; Side \\
& hull waterline length. \\
$\rightarrow$ Triswath & Bulb radius; Bulb depth; Strut length; Strut beam; Main hull waterline beam; Main \\
$\rightarrow$ Hydrodynamic Sustension & hull waterline length. \\
$\rightarrow$ Hydrofoil & Displacement-Speed \\
$\vdots$ & Foil Dynamic lift-Speed ${ }^{\text {a }}$; Draught-Speed ${ }^{\text {a. }}$; Resistance-Speed \\
\end{tabular}

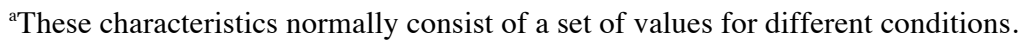

\subsection{Actions required to be undertaken in adopting the proposed approach}

The process of searching the Library for appropriate options and combining these to form new options, which are then presented to the designer, is performed by a number of actions. Actions are split into two types: Fetch Actions that retrieve Item objects from the library and Combine Actions that generate new options by combining sub-options belonging to a number of input actions. These two types can be combined into a hierarchical tree of Actions with Combine Actions as branches and Fetch Actions as leaves, as shown in Figure 4. This differs from the iconic representation shown in Figure 2, since a two stage combination process is employed to, firstly, develop combined FloatMove options and, then, combined Float-Move-Infrastructure options. 


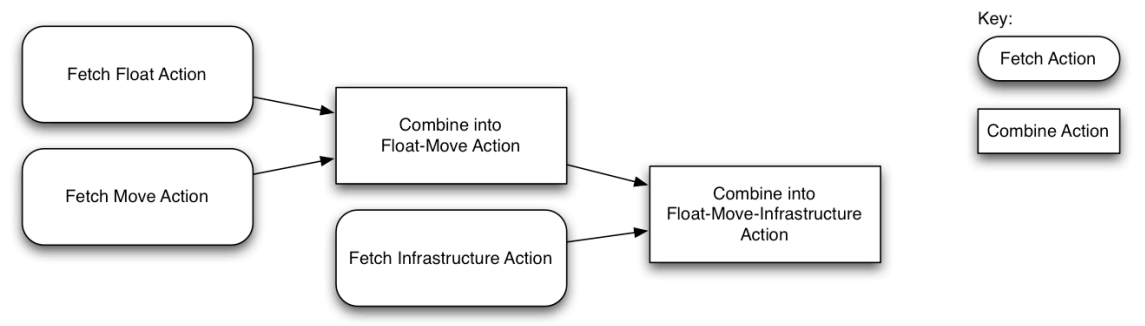

Figure 4 - Example Hierarchical Tree of Fetch and Combine Actions for the Improved Implementation of the Library Method

There are obvious dependencies between actions within this tree structure. However, the current approach allows the impact of these dependencies to be minimised by splitting each action into a number of operations. Dependencies can be defined between operations, in which case the execution of the operations will be delayed until all preceding operations are completed. Any operation for which the dependencies are completed can be executed. This allows a computer with multiple processors (or a cluster of multiple computers) in undertake operations in parallel, speeding up overall completion of the tree of actions. Figure 5 illustrates how the actions for the exploratory implementation can be subdivided into a number of operations, allowing their execution to take place in parallel.

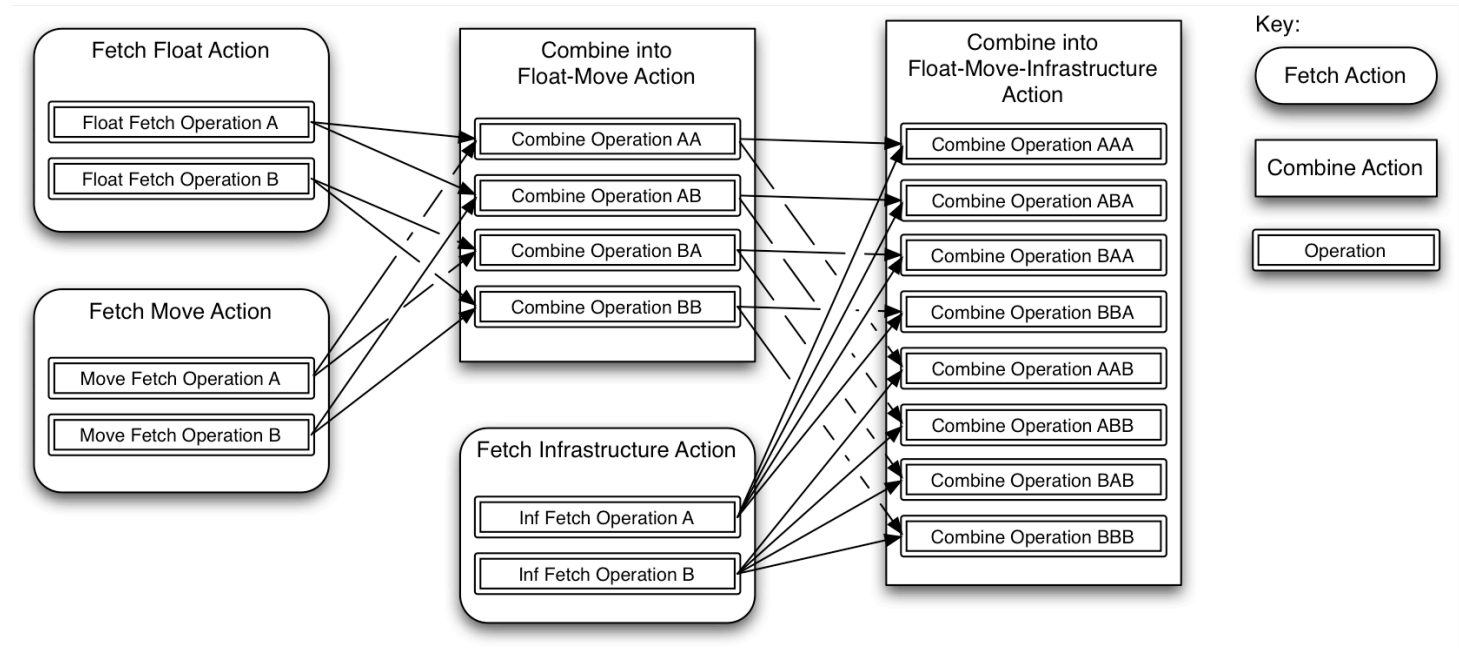

Figure 5 - Evaluating Actions using Multiple Operations in the Improved Implementation of the Library Method Strategies for Down-Selections and Performance Prediction

Figure 5 shows how an Action can be subdivided in to a number of operations to reduce the overall runtime of the Library based approach where each operation has been considered as a sequential process. This process examines a combination of input options in order. As the input items of the Combine Action are actually two or more sets of options then more efficient examination methods are possible. Three possible options shown in Figure 6, are respectively:

A.Combine sub-options; then calculate option characteristics;

B.Calculate sub-options characteristics; then combine acceptable sub-options;

C.Calculate sub-options characteristics; partition into sets; use extremes of sets to eliminate unacceptable solutions.

The first and simplest strategy, shown in Figure 6a, begins by combining two sub-options, the characteristic of interest (which is dependent upon the two sub-options) is calculated and this value checked against a specified requirement (e.g. top speed). The key steps in this strategy are:

1. Using sub-options (squares and triangles) to generate all possible combined options (circles);

2. Calculate the performance of these combined options;

3. Discard unacceptable solutions (red/dark circles). 


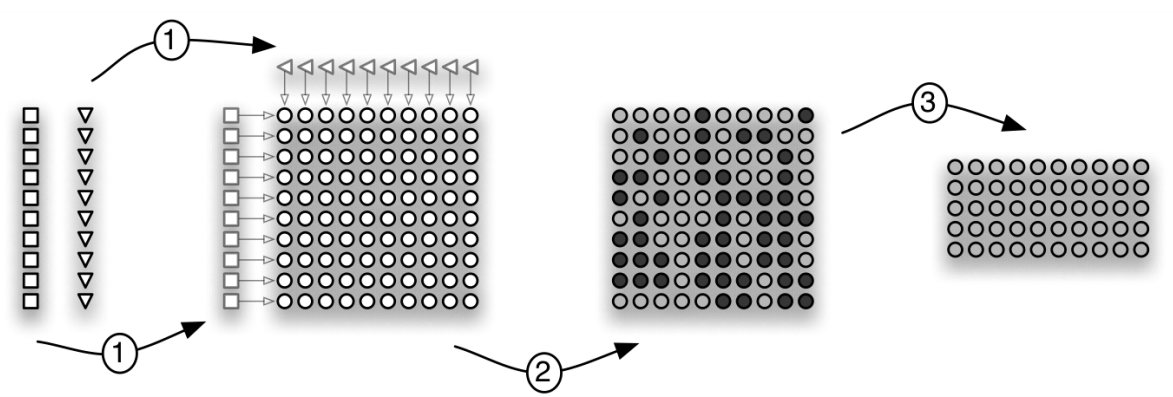

A.Combine sub-options; then calculate option characteristics;

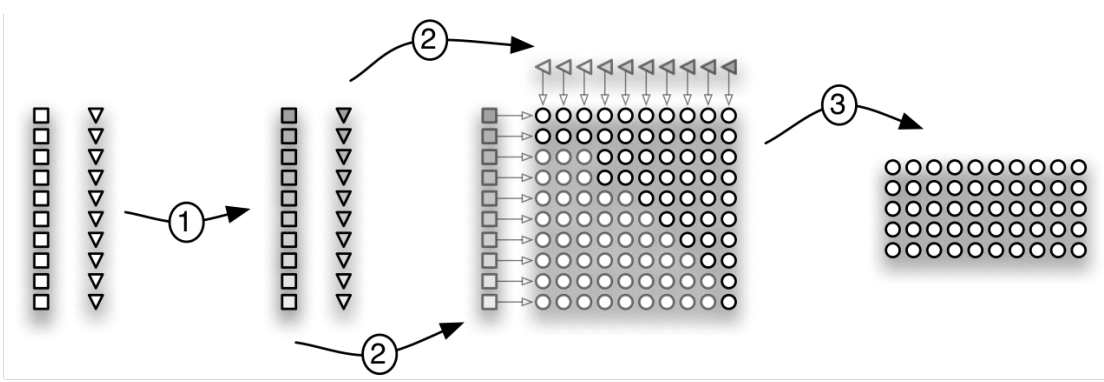

B.Calculate sub-options characteristics; then combine acceptable sub-options;

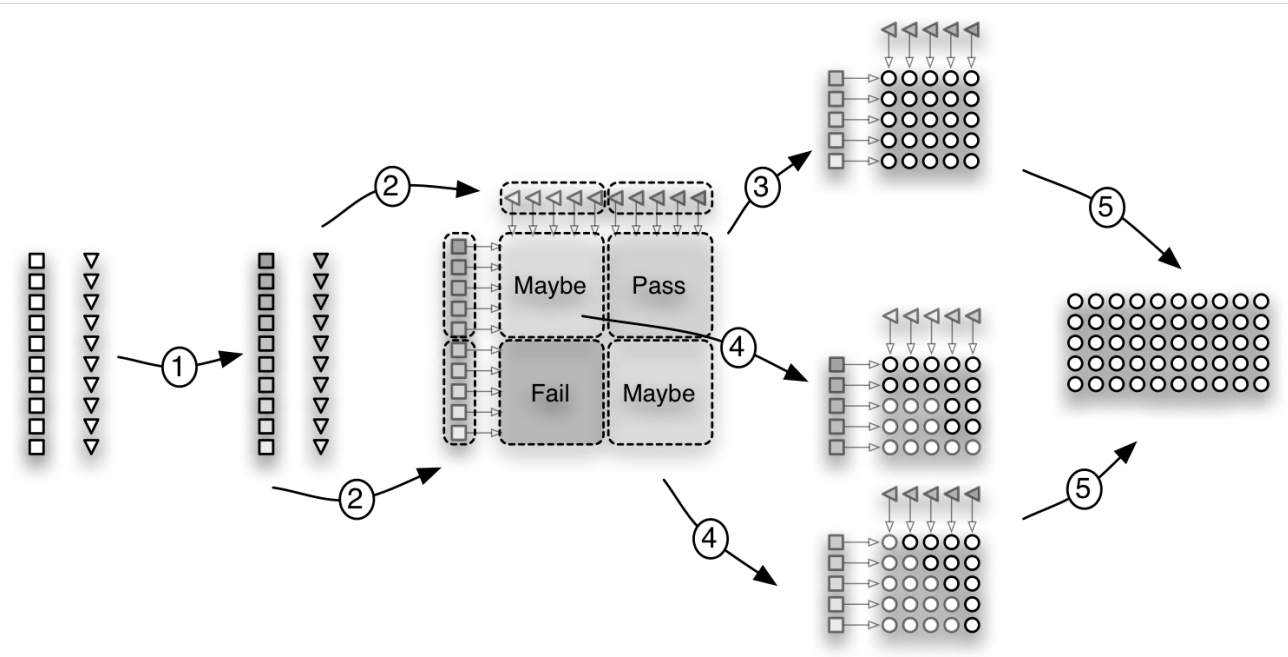

C.Calculate sub-options characteristics; partitions into sets; use extremes of sets to eliminate unacceptable solutions.

\section{Figure 6 - Possible Strategies for Down-Selection in the Library Based Approach}

The next strategy, shown in Figure 6b, relies upon decomposing the top level requirement into two characteristics that can be found for the sub-options. For example, a requirement for a certain maximum speed could be decomposed into required propulsive power at maximum speed (for the Float sub-option) and maximum actual installed power (for the Move sub-option). For each potential combination of sub-options, these two characteristics can be compared and if the constraint is satisfied (e.g. installed power required at maximum speed $<$ maximum installed power provided) a new option can be created. The key steps are:

1. Calculate performance of sub-options;

2. Examine possible combinations of sub-options (squares and triangles); generate combined options (bold circles) where sub-option criteria satisfy constraints;

3. Retain acceptable combined options.

The final strategy also uses sub-option characteristics to down select sub-options but, in addition, sub-options are grouped into sets allowing the number of comparisons to be reduced, as illustrated in Figure 6c. By partitioning the two sets of sub-options into subsets, using the values of the characteristic being examined, the number of comparisons can be radically reduced, since the extremes of the partitioned subsets can be compared. This will determine whether combining the sub-options from these subsets will produce acceptable or unacceptable combined options. This can be illustrated by revisiting the maximum speed requirement considered in the previous paragraph. The set of Float sub-options can be 
partitioned into several subsets, using their value for required propulsive power at maximum speed. Similarly, the set of Move sub-options can be partitioned into several subsets, using their value for maximum actual installed power. Examining these subsets it is possible to identify its extreme values, which are the maximum and minimum power each subset option either provides or requires. The extremes of these subsets can then be compared for each pair of Move and Float subsets (by examining the smallest installed propulsive power of the Move subset relative to the largest power requirements of the Float subset) allowing the identification of the pairs of subsets that are wholly acceptable, wholly unacceptable and those that will contain both unacceptable and acceptable combined options. This information can be used to speed up the processing of combinations of sub-options. The key steps are:

1. Calculate the performance of sub-options;

2. Partition sub-options into subsets, then examine the limits of the subsets to determine if sub-options would satisfy constraints;

3. For subsets that clearly satisfy the constraints, generate all combined options;

4. For a subset that may satisfy the constraints, each option is then examine individually (using strategy B), generating combined options (bold circles) where sub-option criteria satisfy constraints;

5. Retain acceptable combined options.

Figure 6 indicates that the three different approaches require a different number of operations to complete the combination and down selection of a number of options. Table 3 illustrates the significant variation of down selection and performance prediction steps that occur for the different down selection strategies. These values illustrate a library containing 1000 sub-options for each of two functions and the assumption that half the combined options are acceptable. This table shows a marked decrease in both the number of times the performance prediction methods must be applied and also the number of comparisons that have to be performed.

Table 3 - Example of the Variation in Sub-Option Combination and Performance Prediction for different Down Selection Strategies

\begin{tabular}{lccc}
\hline Down Selection Strategy & A & B & C \\
\hline Performance Predictions & $1,000,000$ & 2,000 & 2,000 \\
Sub-Option Comparisons & $1,000,000$ & $1,000,000$ & $500,000^{\mathrm{a}}$ \\
Comparisons of Sub-Option Sets & - & - & 4 \\
Sub-Option Combinations & 500,000 & 500,000 & $500,000^{\mathrm{b}}$ \\
\hline
\end{tabular}

${ }^{a}$ Of which 250,000 are acceptable.

${ }^{b}$ With 250,000 from the comparison of sets and 250,000 from the comparison of sub-options.

\subsection{An Example Method Demonstrating the Proposed Approach}

Before the Library based approach can be used to explore a set of options, the Library must be populated with data. In this case Float, Move and Infrastructure sub-options were developed then stored in the library. The tools used to synthesise the sub-options will not be described in detail here, however a brief description of aspects key to each Float sub-option is provided below, as an example of the data incorporated into each sub-option:

- Generation of the hullform geometry;

- Resistance and propulsive power requirements;

- Weight and volume estimation of items within the Float functional group;

- Intact stability analysis for large angles against appropriate standards;

- Seakeeping performance in head seas.

It should be noted that each Float sub-option took in the region of 170-210 seconds to be generated and evaluated, using a number of linked, automated programs running on a $2.13 \mathrm{GHz}$ Dell Precision M70 laptop computer.

Sub-options were developed for monohull, catamaran and trimaran hullform styles, with representative image shown in Figure 7. Using this tool 3787 sub-options were developed, this comprised of 1458 monohull, 1080 catamaran and 1249 trimaran sub-options respectively. All 3787 Float sub-options are plotted for power required to achieve 40 knots, length and deep displacement against cost, in Figure 8, to demonstrate the wide range of solutions that were generated. 

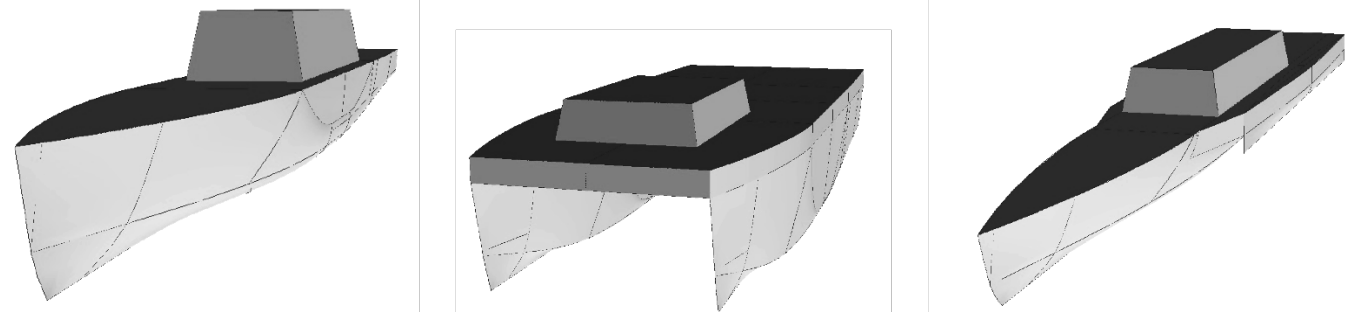

Figure 7 - The Hullform Three Styles Explored for the Float Sub-Options

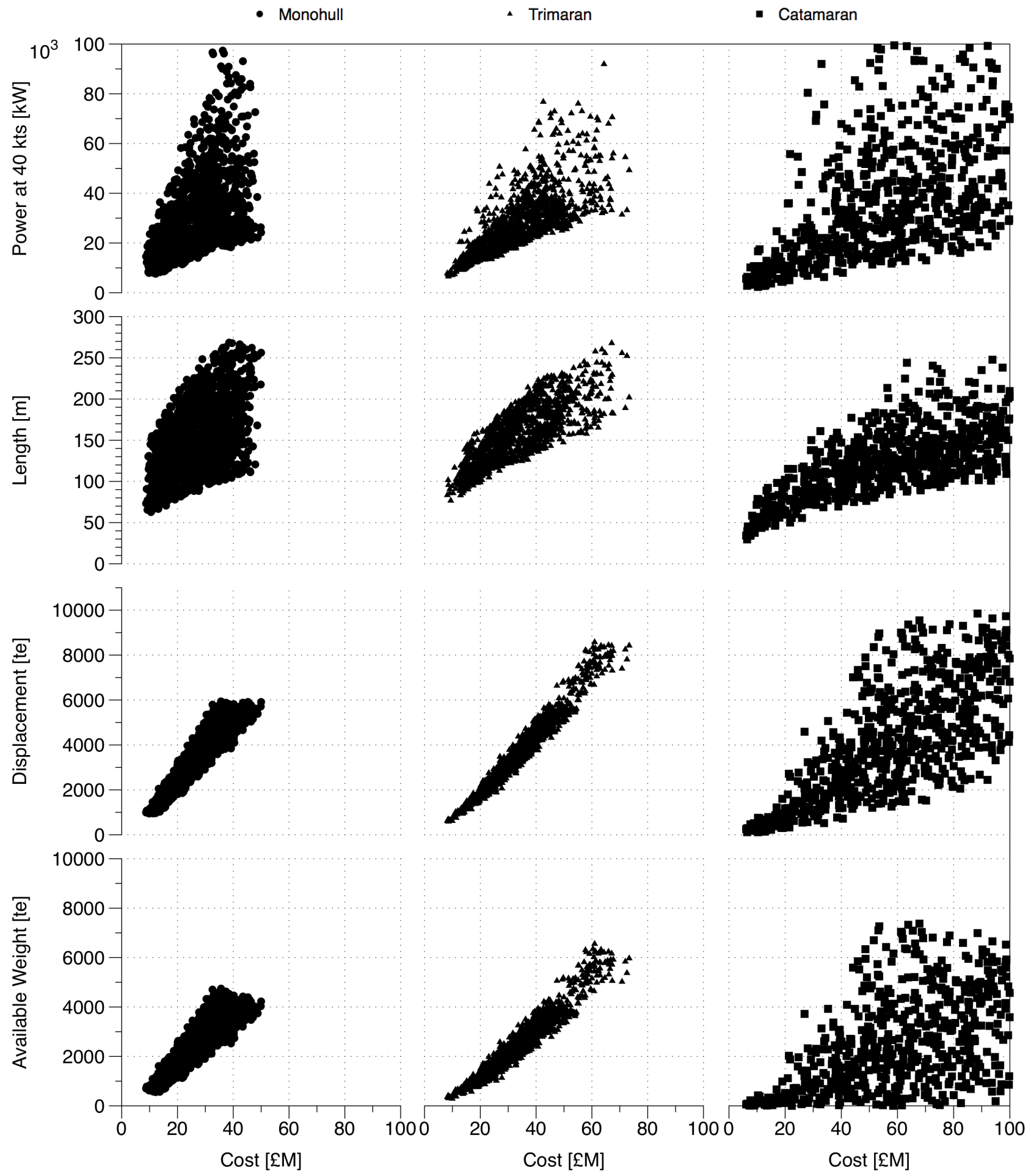

Figure 8 - Power required at 40 knots Maximum Length, Deep Displacement and Available Weight vs. Cost for All Float Sub-Options in the three example Hullform Styles 
The hullform selection that occurred as part of the US Navy's LCS programme [21] was seen to provide a suitable test case. This programme explored different hullforms via a multiphase competition that concluded with the building of two ships with different hullforms. The set of requirements defined at the start of the US Navy LCS design competition was used as a basis for the down selection of potential options. The set of requirements in Table 4 were then developed and used in the example application of the Library approach. Several of these requirements were not explicitly defined in the original LCS requirement [22] but were developed using information derived from an earlier UCL study [23].

Table 4 - Set of Functions and Requirements taken from US Navy LCS Programme [22]

\begin{tabular}{lc}
\hline Function & Threshold Requirement \\
\hline Float & Draught $<6.10$ meters $(20$ feet $)$ \\
Float & RMS vertical velocity in SS4 $<1 \mathrm{~m} / \mathrm{s}$ \\
Float & RMS pitch angle in SS4 $<1.5 \mathrm{deg}$ \\
Infrastructure & Core Crew $<50$ \\
Infrastructure & Max Accommodation $<75$ \\
Combined Float-Move & Range $>1000$ nautical miles at 40 Knots \\
Combined Float-Move & Range $>3500$ nautical miles at 22 Knots \\
Combined Float-Move & Range $>3500$ nautical miles at 16 Knots \\
Combined Float-Move & Range $>500$ nautical miles at 6 Knots \\
Combined Float-Move & Maximum Speed $\geq 40$ Knots \\
Combined Float-Move-Infrastructure & Crew available $\geq$ Crew demand \\
Combined Float-Move-Infrastructure & Weight available $\geq 330$ te \\
Combined Float-Move-Infrastructure & Volume available $\geq 2050 \mathrm{~m}^{3}$ \\
Combined Float-Move-Infrastructure & Total cost (excluding payload) $\leq £ 66 \mathrm{M}$ \\
\hline
\end{tabular}

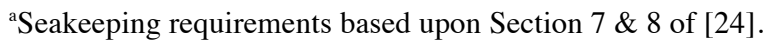

${ }^{\mathrm{b}}$ Developed using payload weight requirements from [23].

${ }^{\mathrm{c} D}$ Developed using payload volume requirements from [23]

${ }^{\mathrm{d}}$ Developed using typical payload costs from [23]. Original target cost (in \$US) converted to match costing data available at UCL [16, 17].

Using the threshold requirements defined in Table 4 the following down selection and combination Actions were implemented:

- Action A - Float sub-options down selection;

- Action B - Move sub-options down selection;

- Action C - Infrastructure sub-options down selection;

- Action D - Float-Move options combination and down selection;

- Action E - Float-Move-Infrastructure options combination and down selection.

These five Actions are described in Sub-Sections 4.2.1 to 4.2.5.

\subsubsection{Action A - Float Sub-Options Down Selection}

The six requirements used to down select the initial library contained 3787 Float sub-options are listed in Table 5. This table also lists the numbers of sub-options that were removed by each of these requirements. After using these requirements to down select the sub-options from the library 2964 Float sub-options remained.

Table 5 - Float Requirements Applied for the Down Selection of the Float Sub-Options

\begin{tabular}{cccc}
\hline \multicolumn{2}{c}{ Requirement } & & Sub-Options Discarded \\
\hline RMS vertical velocity in & $<$ & $1 \mathrm{~m} / \mathrm{s}$ & 0 \\
SS4 & & $1.5 \mathrm{deg}$ & 0 \\
RMS pitch angle in SS4 & $<$ & $330 \mathrm{te}$ & 21 \\
Displacement & $>$ & $6.10 \mathrm{~m}$ & 52 \\
$\quad$ Draught & $<$ & $2050 \mathrm{~m} 3$ & 41 \\
Available internal & $>$ & $330 \mathrm{te}$ & 188 \\
$\quad$ volume & $>$ & $£ 66 \mathrm{M}$ & 542 \\
Available weight & & & \\
$\begin{array}{l}\text { Procurement cost } \\
\text { excluding combat } \\
\text { system }\end{array}$ & $<$ & &
\end{tabular}

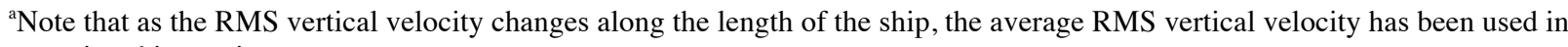
assessing this requirement. 


\subsubsection{Action B - Move Sub-Options Down Selection}

The Library initially contained 2560 Move sub-options. These were down selected to 585 Move sub-options using the two requirements listed in Table 6 . This table also lists the numbers of sub-options that were removed by each requirement.

Table 6 - Move Requirements Applied for the Down Selection of the Move Sub-Options

\begin{tabular}{cccc}
\hline \multicolumn{2}{c}{ Requirement } & & Sub-Options Discarded \\
\hline $\begin{array}{c}\text { Available power } \\
\text { Procurement cost } \\
\text { excluding combat } \\
\text { system }\end{array}$ & $>$ & $7243 \mathrm{~kW}^{\mathrm{a}}$ & 170 \\
\hline
\end{tabular}

${ }^{a}$ This requirement originates from minimum power required by the remaining Float sub-option to achieve the required top speed.

\subsubsection{Action C - Infrastructure Sub-Options Down Selection}

The Library initially contained 583 Infrastructure sub-options. These were down selected to 205 Infrastructure suboptions using the two requirements listed in Table 7 . This table also lists the numbers of sub-options that were removed by each requirement.

Table 7 - Infrastructure Requirements Applied for the Down Selection of the Infrastructure Sub-Options

\begin{tabular}{cccc}
\hline \multicolumn{2}{c}{ Requirement } & & Sub-Options Discarded \\
\hline $\begin{array}{c}\text { Max Crew } \\
\text { Procurement cost } \\
\text { excluding combat } \\
\text { system }\end{array}$ & $<$ & 75 & 378 \\
\hline
\end{tabular}

\subsubsection{Action D - Float-Move Options Combination and Down Selection}

Combining the 2964 Float sub-options and 585 Move sub-options gave a possible 1,733,940 combined Float-Move options. The eight requirements used to down select these combined options are listed in Table 8 . This table also contains the numbers of combined options that were removed by each requirement. In addition to these eight requirements, an additional check on styles was used to remove sub-option with incomparable styles. In this case 51,450 possible combined option that feature a move sub-option unsuitable for the twin hulled catamaran style float sub-option were rejected. This down selection resulted in 136,749 combined Float-Move options remaining.

Table 8 - Combined Float-Move Requirements Applied for the Down Selection of the Combined Float-Move Options

\begin{tabular}{|c|c|c|c|}
\hline \multicolumn{3}{|c|}{ Requirement } & \multirow{2}{*}{$\begin{array}{c}\text { Combined Options Discarded } \\
0\end{array}$} \\
\hline $\begin{array}{c}\text { Available internal } \\
\text { volume }\end{array}$ & $>$ & $2050 \mathrm{~m}^{3}$ & \\
\hline Available weight & $>$ & 330te & 73,539 \\
\hline $\begin{array}{l}\text { Procurement cost } \\
\text { excluding combat } \\
\text { system }\end{array}$ & $<$ & $£ 66 \mathrm{M}$ & 897,993 \\
\hline $\begin{array}{l}\text { Propulsive power } \\
\text { required at } 40 \text { knots }\end{array}$ & $<$ & $\begin{array}{c}\text { Propulsive power } \\
\text { available }\end{array}$ & 366,291 \\
\hline $\begin{array}{l}\text { Propulsive power } \\
\text { required at } 40 \text { knots }\end{array}$ & $<$ & $\begin{array}{l}\text { Maximum power for a } \\
\text { run time of } 25 \text { hours }\end{array}$ & 160,118 \\
\hline $\begin{array}{l}\text { Propulsive power } \\
\text { required at } 22 \text { knots }\end{array}$ & $<$ & $\begin{array}{l}\text { Maximum power for a } \\
\text { run time of } 159 \text { hours }\end{array}$ & 35,458 \\
\hline $\begin{array}{l}\text { Propulsive power } \\
\text { required at } 16 \text { knots }\end{array}$ & $<$ & $\begin{array}{l}\text { Maximum power for a } \\
\text { run time of } 218 \text { hours }\end{array}$ & 29,254 \\
\hline $\begin{array}{l}\text { Propulsive power } \\
\text { required at } 6 \text { knots }\end{array}$ & $<$ & $\begin{array}{l}\text { Maximum power for a } \\
\text { run time of } 83 \text { hours }\end{array}$ & 0 \\
\hline
\end{tabular}


Figure 9 show the procurement cost vs. available weight for Combat Systems for Remaining Combined Float-Move Options, at conclusion of this. This figure shows the remaining Float options separated into three plots by the options for hullform style. While a large number of combined Float-Move options of the trimaran and monohull styles are able to satisfy the requirement imposed up to this stage, a far smaller number of combined options with a catamaran hullform remain acceptable.
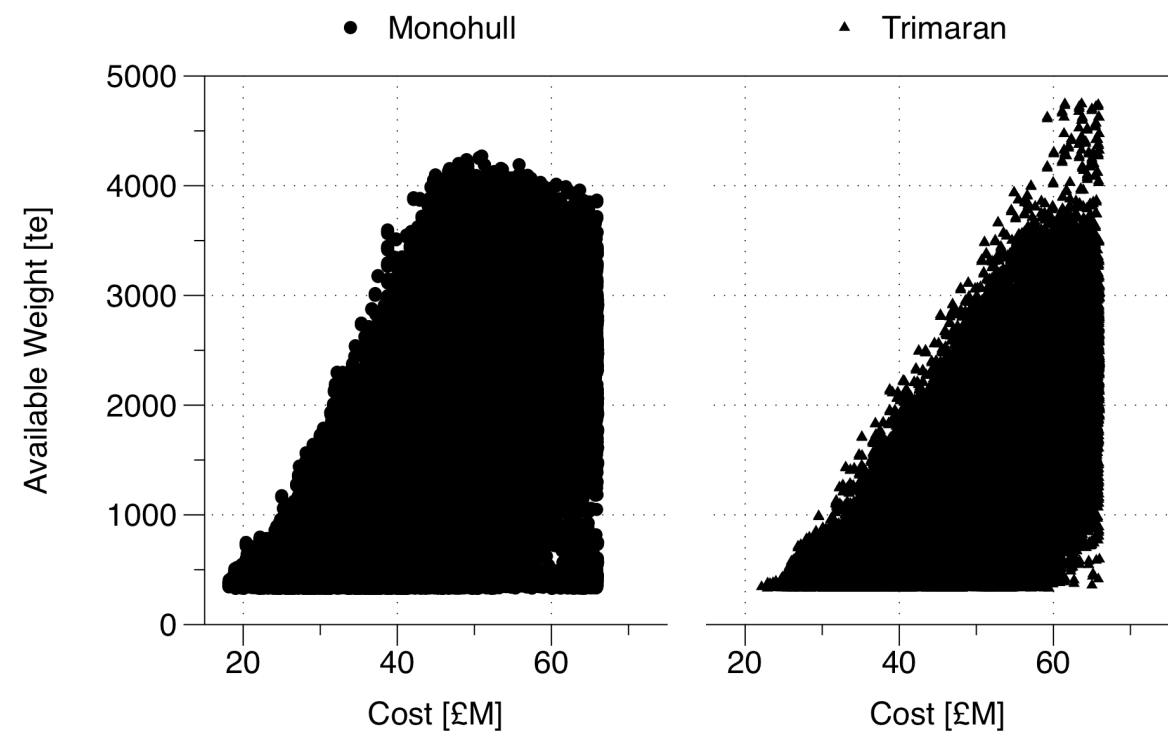

- Catamaran

Figure 9 - Procurement Cost vs. Available Weight for Remaining Combined Float-Move Options, at Conclusion of Action D, showing Three Hullform Styles

\subsubsection{Action E - Float-Move-Infrastructure Options Combination and Down Selection}

Combining the 119,837 combined Float-Move option from the previous step and 205 Infrastructure sub-options gave a possible 24,566,585 combined Float-Move-Infrastructure options. The four requirements used to down select these new combined options are listed in Table 9 together with the numbers of combined options that each requirement removed. This down selection resulted in 25,195 combined Float-Move-Infrastructure options remaining.

Table 9 - Combined Float-Move-Infrastructure Requirements Applied for the Down Selection of the Combined Float-Move-Infrastructure Options

\begin{tabular}{cccc}
\hline \multicolumn{2}{c}{ Requirement } & & Combined Options Discarded \\
\hline $\begin{array}{c}\text { Available internal } \\
\text { volume }\end{array}$ & $>$ & $2050 \mathrm{~m} 3$ & 1,374 \\
$\begin{array}{c}\text { Available weight } \\
\text { Procurement cost } \\
\text { excluding combat }\end{array}$ & $>$ & 330 te & 822,026 \\
$\begin{array}{c}\text { system } \\
\text { Core crew }\end{array}$ & $<$ & $£ 66 \mathrm{M}$ & 281,490 \\
& & 50 & $23,436,500$ \\
\hline
\end{tabular}

At this point these remaining 25,195 acceptable combined Float-Move-Infrastructure options fully satisfied the set of requirement that were applied. The final combination and down selection action are detailed in Figures 10 and 11 , which show the grouping of acceptable options plotted in terms of the weight available for the combat system and procurement cost of the ship solution, excluding the combat system costs. Figure 11 presents as histograms the number of options that remain. From these plots it can clearly be seen that no Catamaran style solution remains but that either a monohull or trimaran style options may provide an acceptable solution for the specified requirements. 


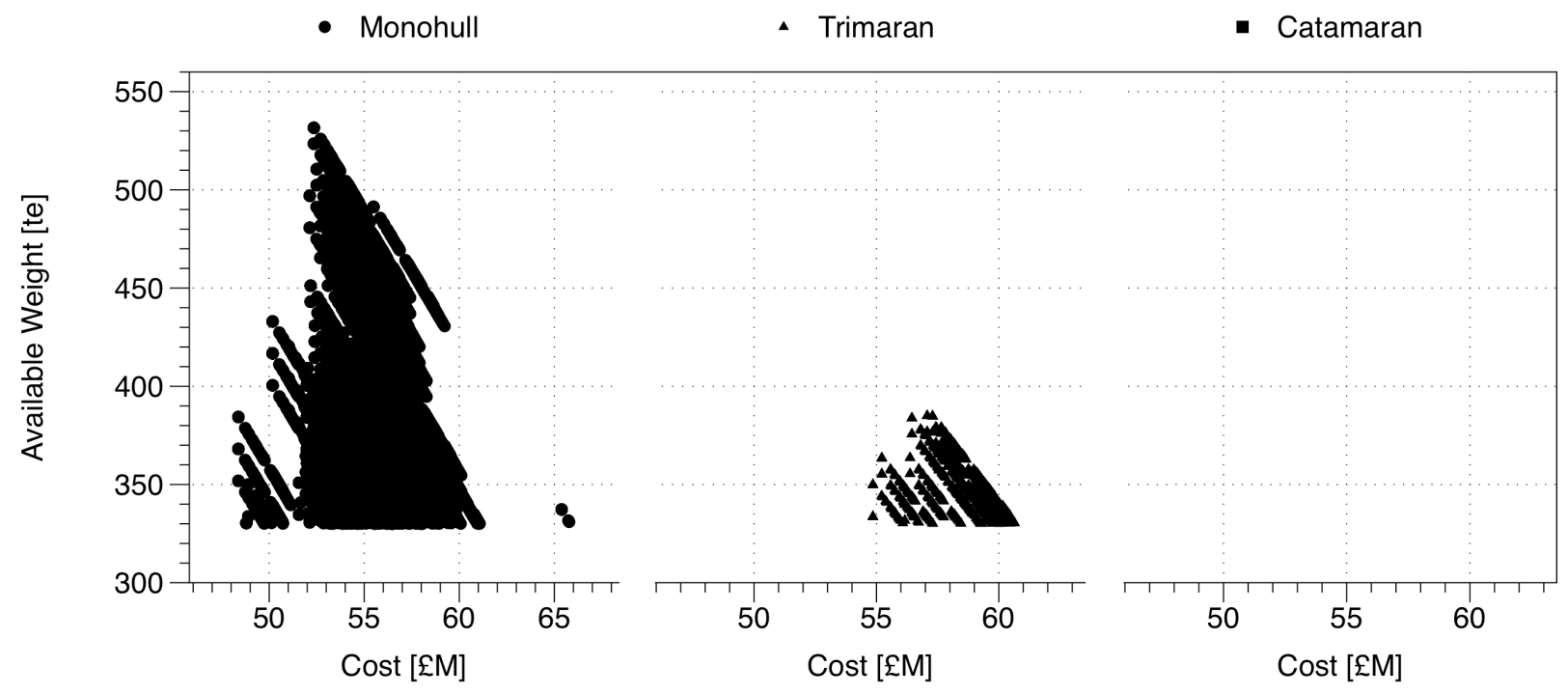

Figure 10 - Procurement Cost vs. Available Weight for Combat Systems for Remaining Combined Float-Move Options, at Conclusion of Action E, showing Three Hullform Styles

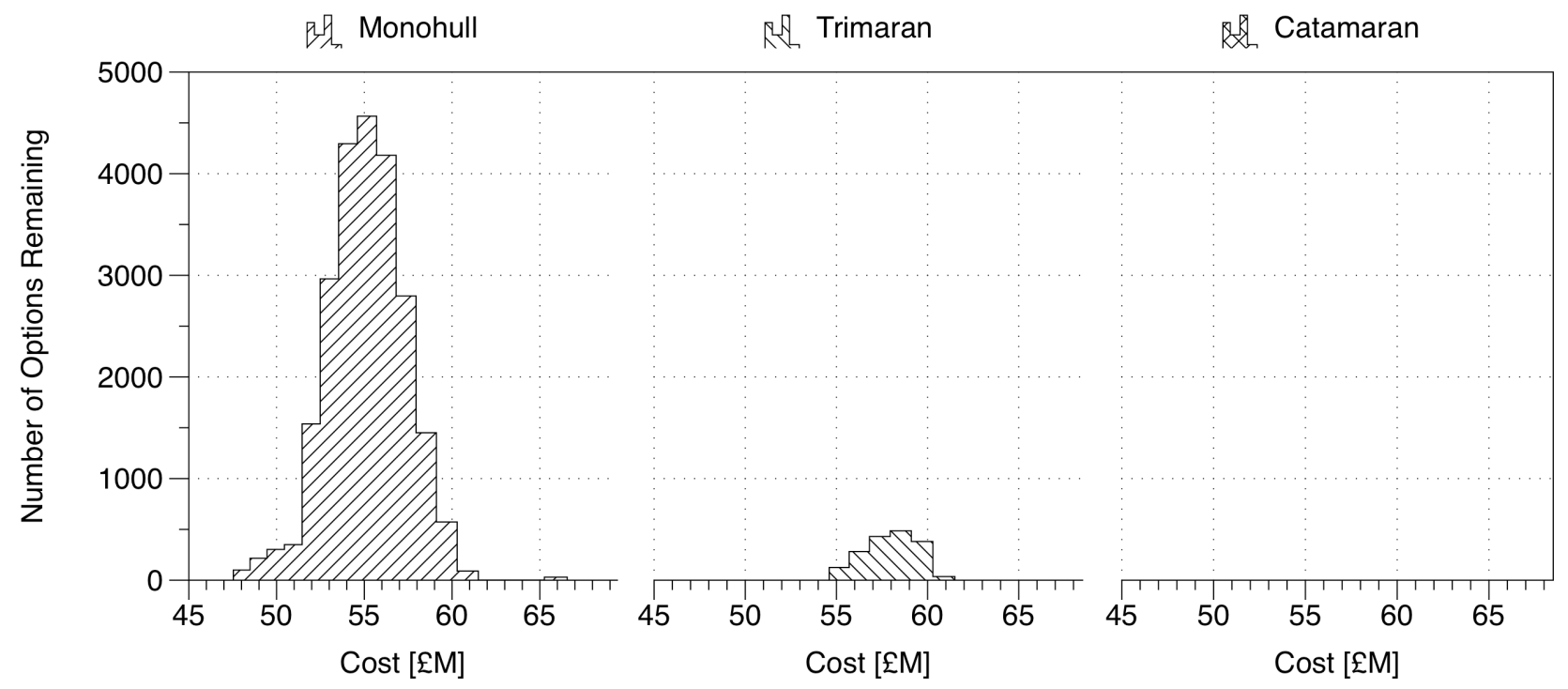

Figure 11 - Procurement Cost for Remaining Combined Float-Move Options, at Conclusion of Action E, showing Two Remaining Hullform Styles (from Three initial Hullform Styles)

As stated previously, the aim of the Library based tool is to provide the designer with information on the range of options that are available. Figure 12 shows how the outputs of a library based ship design tool could be used to better inform a designer. This example demonstrates how the proposed tool could be used in combination with a different design approach, in this case the early stages of a design being developed using the Design Building Block (DBB) Methodology (4), to indicate to the designer how the options relate to the architectural configuration of components spaces in the ship. In this case, a number of outlines illustrating the gross hull geometry of the remaining options (i.e. those generated by the library based tool, which have not been removed by the requirements input by the designer) are shown. As the designer begins to define and develop the design (in this case using a configuration driven tool) additional constraints will emerge-i.e. positioning Fight items along an upper deck which may then define a minimum length or machinery layout which may drive beam at certain longitudinal locations. These new constraints can be used to further resolve the feasible options and provide the designer with reassurance that the emergent design 'makes sense'. 


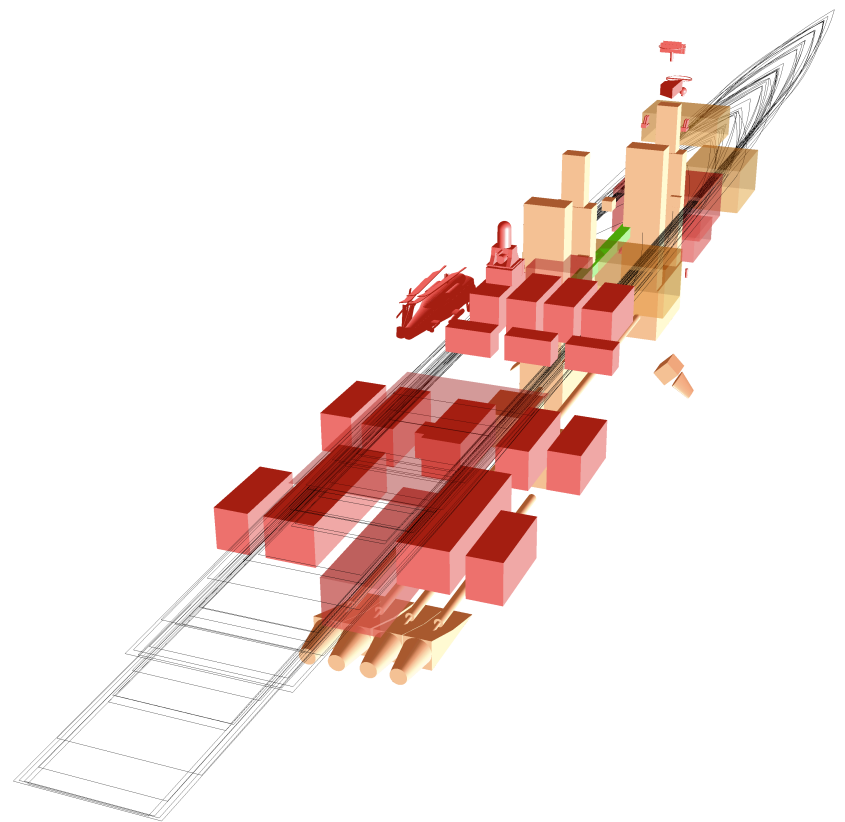

a) Monohull

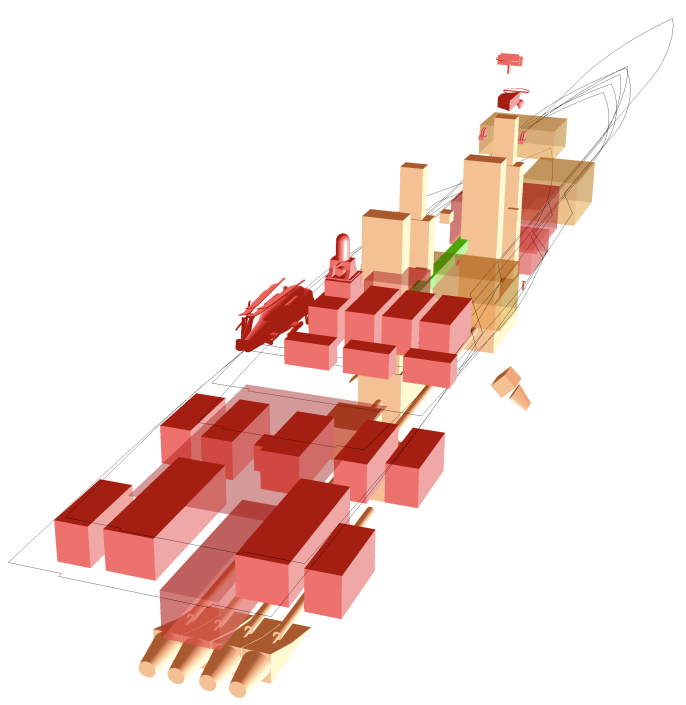

b) Trimaran

Figure 12: Illustrative Example of Integration of Library based approach with Design Building Block approach

\section{DISCUSSION}

\subsection{Practicality of the Approach}

Although the Library based approach is conceptually different from existing design methods it is based upon a simple concept. A developed implementation of the Library based tool would be readily usable by a designer. It would allow a designer to rapidly apply the tool to develop their understanding of the solution space at the outset of the design process. The Library based tool could also act as a central repository of design information within a large design team (or organisation). Design studies or sub-option studies could be added to the library over time, allowing the design team to retain and develop an extensive body of design knowledge.

The simple and flexible method underpinning the Library based approach provides the ability to manage arbitrary information, allowing different ship styles to be easily compared. During the process of developing the sub-options in the Library significant difficulties were experienced due to a lack of available data or appropriate analysis tools, particularly for sub-options belonging to the Float function. This was due to the relative immaturity of most non conventional hullform styles, such as catamarans and trimarans. However, this should not theoretically prevent such options being chosen where they have clear advantages over the conventional.

One substantial benefit of the Library based approach is the rich variety of design data that it is able to store. For example, the current implementation has been shown to be able to store sub-option information, such as ship motions and power-speed data, which allows the designer to gain insights in the performance of prospective solutions. This can then provide the designer with information on the likely performance that can be achieved by a range of sub-options. As this data is pre-generated, the designer is able to rapidly access information normally not available until later in the design process. This has the potential to help guide designers as they explore a wider range of potential options at the outset of the design process.

\subsection{Implementations Speed}

The results from Table 10 show an example of the run time for the tool incorporating the Library based approach described in this paper. These times were obtained for each of the five Action steps, detailed in the previous section, when running the implementation on a MacBook Pro 2.4 GHz Laptop with 2GB of random access memory. 
Table 10 - Run time for the Library based approach

\begin{tabular}{lr}
\hline Actions & Run Time (sec.) \\
\hline A - Float Sub-Options Down Selection & 38.11 \\
B - Move Sub-Options Down Selection & 7.75 \\
C - Infrastructure Sub-Options Down & 2.98 \\
Selection & \\
D - Float-Move Options Combination & 137.49 \\
and Down Selection & \\
E - Float-Move-Infrastructure Options & 237.75 \\
Combination and Down Selection & \\
\hline
\end{tabular}

However, as the library grows (both in terms of the number of options stores within it and the number of characteristics per option) performance penalties or limitations will accumulate and the total run time will increase. A large library of sub-options is needed to capture sufficient granularity to describe a wide range of ships and this will result in a large number of independent variables through which they are to be described. Furthermore, as the library grows in size, an increasing number of sub-options has the potential to generate an unmanageable number of combined options.

This paper has demonstrated how requirements, adapted from a real project, can be used to filter the available options, successfully reducing the total number of options to be considered. Further, by employing parallelisation and efficient down selection strategies, significant reductions in runtime can be achieved. Additional down selections may be completed earlier if information on the remaining combination or sub options were available (i.e. Action B of the example demonstrated in Section 4.2.2 shows the down selection of a number of Move sub-options using the requirement for "Available power $>7243 \mathrm{~kW}$ " itself derived from the minimum power required by the Float sub-options to achieve the specified 40 knots).

\subsection{Integrating the Proposed Tool with Design Building Block Approach}

Referring back to Andrews' lists of features necessary in a proposed methodology capable of fully supporting the initial ship design process enables an assessment of the Library based approach's appropriateness. This comparison considers the Library based approach assuming a link could be readily implemented to a configuration based design method (namely the Design Building Block approach). For each of Andrews [13] features a response is provided below based on the demonstration provided in this paper:

1. Believable solutions: the options proposed by the Library based approach satisfy a set of constraints that a designer may define. These constraints could be used to ensure that the developed solutions are technically balanced and the combination/discard mechanism eliminates unreasonable options;

2. Coherent solutions: Integrating the Library based approach with a visual representation (as shown in Figure 12) would allow a dialogue with the customer beyond simple numerical measures of performance and cost. The combined Library and Design Building Block approaches together would enable the designer to present the customer/requirement owner with an integrated configuration based design, which additionally is based on the rapid exploration of a very wide and differing range of options obtained from using the library;

3. Open methods: The rapid manner in which the options are down selected would enable the designer to respond quickly to issues likely to be raised by the customer/requirement owner/user group. Coupling this method with an appropriate visualisation and design tool should allow rapid exploration of options, improving the design team's responsiveness to customer/requirement owner/user group queries and hence communication with these groups would assure all parties that a comprehensive exploration has been undertaken;

4. Revelatory: The proposed Library approach could be used to quickly identify numerical design drivers from the start of the design process. But to realise its full potential, as an aid to effective design exploration, links to the DBB approach or equivalent, as suggested by Figure 12, would need to be more fully realised;

5. Creative: Compared to other ship design methods, by allowing the designer to postpone the selection of hullform style, this approach allows the designer to keep options open until later in the design process, fostering the development of alternatives that may have previously been rejected from consideration due to the difficulty in assessing such options alongside conventional (monohull) options;

\section{CONCLUSIONS}

The design method this research presented has adopted a simple, but flexible approach to ship concept design extended beyond just monohull style hullform selection. This approach is seen as desirable due to the unique challenges occurring in the requirement elucidation stage of the ship design process, when compared to the remainder of the ship design process. In tailoring the Library based approach to tackle these challenges, the ship definition is necessarily limited. It is not therefore seen to be realistic as a complete end-to-end design method for use beyond concept and possibly feasibility 
(Assessment in current UK Ministry of Defence parlance [25]) whole ship design process (i.e. developing the design for approval and manufacture). Instead, the proposed tool is well suited to assisting the designer in rapidly and more extensively exploring the solution space in the preliminary phase of the ship design process. As a consequence, it can assist the designer in addressing the key task of requirement elucidation.

\subsection{Further Work}

The Library based approach outlined in this paper is considered to provide a first step on towards a tool able to better satisfy Betts' and Andrews' lists of features required in a tool or method to support the early stages of the ship concept design process, summarised at the end of Section 1. However, further work is seen as required for it to be incorporated in the preliminary ship design process of practicing naval ship design organisations, as is summarised below:

- Demonstration of the applicability of the specific method to a problem with a greater range of hullform styles and differing ship roles. This would require a range of comparable designs to be developed;

- Exploration of methods of presenting the designer with information on the styles of options, which still remain as acceptable through the down selection process;

- The testing of the design method against ship concept designs produced by conventional methods for practicing design houses;

- Exploration of data management mechanisms, which could better support larger collections of sub-options and combined ship options.

\section{Acknowledgement}

The research, which this paper draws on, was made possible by the funding of the first author's PhD by the Professor of Naval Architecture at UCL.

\section{References}

1. McDonald, TP and Andrews, DJ. 'Hullform Comparison and Selection During Requirement Elucidation in the Concept Stage of the Ship Design Process'. Tenth International Marine Design Conference (IMDC'09). 2009.

2. Andrews, DJ, Cudmore, A, Humble, P and Wilson, D. 'SUBCON - A new approach to submarine concept design'. RINA Warship '96 - Naval submarines. Royal Institution of Naval Architects, London, 1996.

3. Andrews, DJ and Dicks, C. 'The Building Block Design Methodology Applied to Advanced Naval Ship Design'. Sixth International Marine Design Conference (IMDC’97). Newcastle, June 1997.

4. Andrews, DJ and Pawling, R. 'The Application of Computer Aided Graphics to Preliminary Ship Design'. Ninth International Marine Design Conference (IMDC'06), volume 2. Ann Arbour, Michigan, May 2006.

5. Andrews, DJ. 'Synthesis in Ship Design'. Ph.D. thesis, University of London, 1984.

6. Andrews, D. and Casarosa, L. and Pawling, R. and Galea, E. and Deere, S. and Lawrence, P., "Integrating Personnel Movement Simulation into Preliminary Ship Design”, Proceeding RINA Conference on Human Factors in Ship Design, Safety and Operation, London, March 2007

7. Andrews, DJ. 'Marine Design - Requirement Elucidation rather than Requirement Engineering'. Eighth International Marine Design Conference (IMDC’03). Athens, May, 2003.

8. Andrews, DJ, (Ed.), Keane, RG, Lamb, T, Sen, P and Vassalos, D. 'State of the Art Report: Design Methodology'. Ninth International Marine Design Conference (IMDC’06), volume 1. Ann Arbour, Michigan, May 2006.

9. Nowacki, H. 'Development in Marine Design Methodology: Roots, Results and Future Trends', Tenth International Marine Design Conference (IMDC’09). 2009.

10. Andrews, DJ. ‘Preliminary Warship Design'. RINA Transactions, volume 136:pp. 37-55, 1994.

11. van Oers, B, Stapersma, D and Hopman, H. 'Issues when selecting naval ship configurations from a Paretooptimal set'. Presented at the 12th AIAA/ISSMO Multi-disciplinary Analysis and Optimization Conference. AIAA, Victoria, British Columbia, Canada, September 2008. 
12. Betts, CV. 'Development in Ship Design from a Naval Perspective'. Seventh International Marine Design Conference (IMDC'00). Korea, 2000.

13. Andrews, DJ. 'A Creative Approach to Ship Architecture'. International Journal of Maritime Engineering, volume 142, September 2003.

14. Andrews, DJ. 'A Comprehensive Methodology for the Design of Ships (and Other Complex Systems)'. Proceedings of the Royal Society A, volume 454:pp. 187-211, 1998.

15. Atzeni, P, Ceri, S, Paraboschi, S, and Torlone, R. 'Database Systems: Concepts, Languages and Architectures'. McGraw-Hill, London, 1999.

16. UCL. "MSc Ship Design Procedure.” Department of Mechanical Engineering, University College London, 2002.

17. UCL. "MSc Ship Design Data Book.” Department of Mechanical Engineering, University College London, 2004.

18. Tan, K. \& Sen, P. 'The Application of a Decomposition and Reuse Approach in Marine Design'. Practical Design of Ship and Other Floating Structures (PRADS), Shanghai, China, September 2001

19. Manley, D. 'Warship Vulnerability Reduction and The Littoral Environment'. RINA Warship 2004 Conference: Littoral Warfare \& The Expeditionary Force, London, June 2004.

20. Maroju, S, Syamsundar, S, DeLorme, M, Vasudevan, S, Datla, R, Pennotti, M and Bruno, M. 'A value focused approach to ship design synthesis, analysis, and selection'. In 'World Maritime Technology Conference 2006 (WMTC2006)', The Institute of Marine Engineering, Science and Technology, London, 2006.

21. Long, D and Johnson, S. 'Case Studies in National Security Transformation: The Littoral Combat Ship From Concept to Program'. Technical Report 7, Center for Technology and National Security Policy, National Defense University, Washington, DC, March 2007.

22. US Navy. 'Preliminary Design Interim Requirement Document for Littoral Combat Ship (LCS) Flight 0'. Technical Report N763F-S03-026, US Navy, February 2003.

23. McDonald, TP, Greig, AR and Rusling, S. 'A Comparative Study of the US Navy Littoral Combat Ship'. RINA Conference on the Design and Operation of Trimaran Ships. Royal Institution of Naval Architects, London, April 2004.

24. Eriksen, JH (ed.). NATO Standardization Agreement: Common Procedures For Seakeeping in the Ship Design Process. NATO Allied Naval Engineering Publication (ANEP), December 2000.

25. UK Ministry of Defence. 'The MoD Acquisition Handbook: Faster, Cheaper, Better; A guide to Smart Procurement'. 4th Edition, 2002. 